\title{
Variação nictemeral da clorofila $a$, produção primária do fitoplâncton e fatores ambientais da região de Ubatuba (Lat. $23^{\circ} 30^{\prime} \mathrm{S}$ Long. $45^{\circ} 06^{\prime} \mathrm{W}$ )
}

\author{
Clovis TEIXEIRA* \& Salvador Airton GAETA*
}

Instituto Oceanográfico da Universidade de São Paulo

(Caixa Postal 9075, 01051 São Paulo, SP)

\begin{abstract}
- Abstract: A series of experiments with natural phytoplankton populations was carried out to study the diel variation of chlrophyll $a$, primary production and some environmental factors. Samples were collected from surface over a period of 24 hours and always from one fixed station located in Flamengo Inlet, Ubatuba region, southern Brazil. The experiments were performed in situ and simulated conditions to verify the patterns of diel cycles of both biotic and abiotic factors. The results obtained showed that diel variations were markedly pronounced mainly in relation to primary production and chlorophyll $a$. Diel variations of biological factors seems to be due to exogenous and endogenous phenomena.
\end{abstract}

- Descriptors: Photosynthesis, Chlorophyll $a$, Diel variation, Primary production, Environmental conditions, Ubatuba: SP.

- Descritores: Fotossíntese, Clorofila $a$, Variação nictemeral, Produção primária, Fatores ambientais, Ubatuba: SP.

\section{Introdução}

Um dos aspectos fundamentais para a obtençāo de dados sobre a produção primária de um ecossistema marinho com maior acurácia e de alto significado para a confecçāo de modelos, refere-se aos conhecimentos obtidos a partir dos estudos e da determinação da periodicidade nictemeral (atividades cíclicas de $24 \mathrm{~h}$ compreendidas pelo dia e noite), não só do fitoplâncton, como também das características ambientais. Os ritmos biológicos caracterizam-se pela recorrência, a intervalos regulares, de eventos bioquímicos, fisiológicos e comportamentais (Aschoff, 1981).

Desde o trabalho de Doty \& Oguri (1957), sugerindo a existência do ritmo nictemeral na atividade fotossintética do fitoplâncton marinho, têm sido apresentados inúmeros estudos de campo e de laboratório, documentando o fenômeno. Várias pesquisas têm demonstrado que a capacidade fotossintética (F max) assim como a eficiência fotossintética (a) do fitoplâncton natural variam durante o dia geralmente com valores máximos e com valores mínimos ocorrendo a noite (Gargas et al., 1979; Prezelin \& Ley, 1980; Teixeira, 1980;1982, etc.). Muito embora seja reconhecido

(*) Professor Associado do Centro de Biologia Marinha - USP. Contr. $n^{2} 723$ do Inst. oceanogr. da Usp. que as oscilações nictemerais periódicas da capacidade fotossintética sejam em parte controladas pelo "relógio biológico" da célula (Hastings et al., 1961, etc.), os fatores ambientais podem também alterar significativamente a natureza deste ritmo.

A variação nictemeral da fotossíntese pode influir decisivamente sobre dois eventos de significância concernente a um ecossistema aquático: 1) sobre a determinação da produção primária quando se considerar a amplitude do ritmo, assim como o período do dia escolhido para conduzir as medidas da produção primária afetando, por conseguinte, os cálculos da mesma; 2) com relação à amplitude e/ou fase do ritmo da fotossíntese, poder refletir também o estado fisiológico e, em particular o status do fitoplâncton em relaçấo aos nutrientes (Harding et al., 1982).

O desenvolvimento deste trabalho objetiva determinar o comportamento das populaçōes naturais do fitoplâncton em termos das variaçōes da fotossíntese e da clorofila $a$ durante o ciclo nictemeral e verificar as possíveis influências exógenas e endógenas sobre a fotossíntese e a clorofila $a$.

\section{Material e métodos}

A área de coletas está localizada na Lat. $23^{\circ} 30^{\prime}$ S Long. $45^{\circ} 06^{\prime} \mathrm{W}$, Brasil (Fig. 1). As coletas foram 
realizadas durante as vinte quatro horas (dia e noite) em oito dias, seguindo-se dois esquemas: 1) a cada três horas a amostra era coletada diretamente da superfície do mar (amostra renovada); 2) no início de cada experimento cerca de 30 a $60 l$ de água eram coletados e armazenados num recipiente de plástico transparente e previamente lavado várias vezes, permanecendo na superfície do mar exatamente no ponto de coleta. Da amostra armazenada, foram retiradas sub-amostras a cada três horas de intervalo, a fim de se realizar os experimentos. Para os experimentos fotossintéticos foram utilizados 12 frascos "pyrex" obedecendo-se o seguinte esquema: dois frascos transparentes e um preto foram enchidos com os dois tipos de amostras (renovadas e armazenadas). Em cada amostra foi adicionada uma ampola de $\mathrm{NaH}^{14} \mathrm{CO}_{3}$, contendo uma atividade de $10,0 \mu \mathrm{Ci}$. A incubaçāo foi de três horas, imediatamente seguida de filtração sob baixa pressẩo, sempre em série de três frascos de maneira concomitante, utilizando-se filtros "Millipore" HA. A incubação simulada foi realizada num incubador contendo seis lâmpadas (Philips W/33-20 W) por gaveta, submetida à circulação de água que permitiu a manutenção da temperatura desejada. O sistema de iluminação proporcionou um fluxo de energia da ordem de $350 \mu \mathrm{E} \mathrm{cm}^{-2}$ min $^{-1}$, medida efetuada com um "quanta-meter" modelo Lambda Li-185.

A radioatividade das amostras foi determinada num espectrômetro de cintilação líquida, modelo TRI-CARB C-2425 da Packard, empregando-se o líquido cintilador (Bray, 1960).

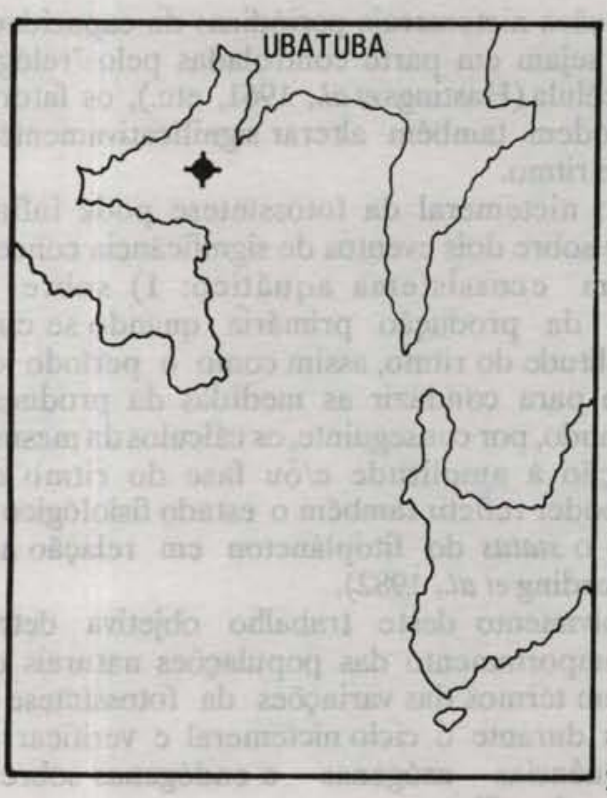

$23^{\circ} 29^{\circ}$

$23^{\circ} 34$

Fig. 1. Mapa da região da Enseada do Flamengo mostrando a posição do ponto de coleta.
A clorofila $a$ total foi determinada segundo Strickland \& Parsons (1968). A radiação solar foi medida usandose um actinógrafo bi-metálico de $\mathbf{R}$. Fuess, seg. Robitzch, calibrado contra um actinógrafo padrão.

A temperatura da água foi determinada com um termômetro com a precisão de $0,1^{\circ} \mathrm{C}$ e o oxigênio dissolvido pelo método de Winkler. A salinidade foi determinada empregando-se um salinômetro Kahlsico, modelo 118 WA-200. O fosfato inorgânico foi determinado segundo Strickland \& Parsons (1968) e o nitrato pelo método de Mullin \& Riley (1955).

\section{Resultados}

\section{Parâmetros Físicos e Químicos}

De um modo geral, dos parâmetros estudados, não foram constatadas grandes variaçōes entre os diferentes meses estudados, ficando evidenciada, contudo, uma variação nictemeral em relação a alguns fatores medidos ou determinados.

\section{Oxigênio Dissolvido}

A concentração de oxigênio dissolvido (Tab. 1) apresentou variaçāo nictemeral com valores máximos mais altos no verão $\left(3,26 \mathrm{a}_{4,96 \mathrm{ml} \mathrm{l}^{-1}}\right)$, sendo que no inverno os valores variaram de 3,78 a $4,80 \mathrm{mll}^{-1}$. Com relaçāo aos valores de saturaçâo, variaram de 70,98 a $110,09 \%$ (Tab. 2), sendo nitidamente maiores durante o verão, provavelmente devido à maior atividade biológica.

Tabela 1. Conćentração de oxigênio dissolvido $(\mathrm{ml} / \mathrm{l})$ da superfície durante as horas de coleta de um dia

\begin{tabular}{lllllllllll}
\hline Hora & FEV. & MAR. & ABR. & JUN. & JUL. & AGO. & MAR. & QUT. \\
\hline $06: 00$ & 4,12 & 4,01 & 3,26 & 3,98 & 4,05 & 4,11 & 3,97 & 4,00 \\
\hline $09: 00$ & 4,29 & 4,75 & 3,97 & 4,05 & 4,30 & 4,38 & 4,63 & 3,99 \\
\hline $12: 00$ & 4,51 & 4,50 & 3,90 & 4,10 & 4,22 & 4,64 & 4,45 & 4,08 \\
\hline $15: 00$ & 4,54 & 4,80 & 3,86 & 4,00 & 4,43 & 4,80 & 4,30 & 3,96 \\
\hline $18: 00$ & 4,12 & 4,96 & 3,88 & 3,85 & 4,30 & 4,73 & 4,41 & 3,95 \\
\hline $21: 00$ & 4,15 & 4,18 & 3,84 & 4,04 & 4,04 & 4,25 & 3,92 & 3,81 \\
\hline $24: 00$ & 4,08 & 3,86 & 3,67 & 3,78 & 4,13 & 4,11 & 3,87 & 3,77 \\
$03: 00$ & 4,00 & 3,95 & 3,77 & 3,90 & 4,05 & 4,09 & 3,49 & 3,45
\end{tabular}


Tabela 2. Porcentagem de saturação de oxigênio dissolvido da superfície durante as horas de coleta de um dia

\begin{tabular}{lllllllllll}
\hline Hora & FEV. & MAR. & ABR. & JUN. & JUL. & AGO. & MAR. & OUT. \\
\hline $06: 00$ & 91,35 & 88,91 & 71,80 & 80,40 & 80,83 & 80,11 & 82,19 & 82,30 \\
\hline $09: 00$ & 96,83 & 103,95 & 89,01 & 81,00 & 89,02 & 85,31 & 102,66 & 82,09 \\
\hline $12: 00$ & 103,44 & 103,21 & 87,44 & 82,82 & 87,37 & 93,73 & 98,66 & 85,35 \\
$15: 00$ & 103,21 & 110,09 & 87,44 & 80,80 & 91,71 & 96,96 & 95,34 & 83,01 \\
$18: 00$ & 93,00 & 97,70 & 85,46 & 77,77 & 97,92 & 93,84 & 97,78 & 81,27 \\
$21: 00$ & 93,67 & 94,35 & 84,58 & 80,80 & 83,64 & 84,32 & 86,80 & 78,39 \\
\hline $24: 00$ & 92,09 & 85,58 & 79,43 & 76,36 & 85,50 & 81,54 & 85,80 & 77,57 \\
\hline $03: 00$ & 90,29 & 87,58 & 80,21 & 77,68 & 82,31 & 79,72 & 77,38 & 70,98 \\
\hline
\end{tabular}

\section{Salinidade}

Os valores referentes à salinidade (Tab. 3), variaram de 32,06 a $34,70 \%$, nāo ficando definida, entretanto, nenhuma variação nictemeral bem determinada.

\section{Temperatura da água}

A maior variação nictemeral encontrada foi de $3,30^{\circ} \mathrm{C}$ (abril/1978) e a menor foi de $0,15^{\circ} \mathrm{C}$ (março/1979). Sazonalmente, os mesmos valores foram registrados entre junho e agosto (mínimo de $21,0^{\circ} \mathrm{C}$ ) e o máximo ocorreu $\mathrm{em}$ fevereiro/1978, atingindo $30,50^{\circ} \mathrm{C}$ (Tab. 4).

Tabela 3. Salinidade (\%o) da superfície durante as horas de coleta de um dia

\begin{tabular}{lllllllllll}
\hline Hora & FEV. & MAR. & $\begin{array}{c}1978 \\
\text { ABR. }\end{array}$ & JUN. & JUL. & AGO. & MAR. & a. \\
\hline $06: 00$ & 34,37 & 34,81 & 33,57 & 33,78 & 34,10 & 32,38 & 34,20 & 33,70 \\
\hline $09: 00$ & 34,20 & 34,41 & 33,40 & 33,84 & 33,53 & 33,40 & 34,18 & 32,80 \\
\hline $12: 00$ & 34,45 & 34,57 & 32,97 & 33,87 & 33,46 & 33,14 & 34,35 & 33,10 \\
\hline $15: 00$ & 34,40 & 34,48 & 33,49 & 33,64 & 34,13 & 33,19 & 33,90 & 34,05 \\
\hline $18: 00$ & 34,15 & 34,63 & 33,19 & 33,61 & 34,00 & 32,98 & 34,10 & 34,10 \\
\hline $21: 00$ & 34,00 & 34,54 & 33,13 & 32,83 & 33,79 & 32,06 & 34,15 & 34,17 \\
\hline $24: 00$ & 34,20 & 34,70 & 33,23 & 33,51 & 33,83 & 32,38 & 34,20 & 33,95 \\
\hline $03: 00$ & 34,35 & 34,70 & 32,83 & 33,42 & 34,01 & 32,43 & 34,17 & 33,89 \\
\hline
\end{tabular}

Tabela 4. Temperatura $\left({ }^{\circ} \mathrm{C}\right)$ da superfície durante as horas de coleta

\begin{tabular}{|c|c|c|c|c|c|c|c|c|}
\hline \multirow[b]{2}{*}{ Hora } & \multicolumn{6}{|c|}{1978} & \multicolumn{2}{|c|}{1979} \\
\hline & FEV. & MAR. & ABR. & JUN. & JUL. & AGO. & MAR. & का. \\
\hline $06: 00$ & 27,80 & 28,20 & 28,10 & 23,10 & 22,00 & 21,00 & 28,00 & 24,00 \\
\hline $09: 00$ & 28,40 & 29,80 & 29,30 & 22,50 & 23,50 & 22,00 & 28,00 & 24,10 \\
\hline $12: 00$ & 30,00 & 30,10 & 29,30 & 22,50 & 24,00 & 23,00 & 28,10 & 24,70 \\
\hline $15: 00$ & 30,50 & 30,15 & 28,40 & 23,00 & 24,00 & 23,00 & 28,15 & 24,65 \\
\hline $18: 00$ & 29,70 & 30,00 & 28,30 & 23,00 & 24,00 & 22,00 & 28,15 & 23,95 \\
\hline 21:00 & 29,00 & 29,00 & 28,00 & 22,50 & 24,00 & 22,00 & 28,10 & 23,80 \\
\hline $24: 00$ & 28,30 & 28,20 & 27,00 & 22,50 & 24,00 & 22,00 & 28,10 & 23,85 \\
\hline 10,9 & 10.9 & 60.8 & 78.0 & $90,8=$ & $34,45=$ & $3 t, 0=$ & $4,0.0$ & bets \\
\hline 03:00 & 28,20 & 28,00 & 26,00 & 22,30 & 23:30 & 21,00 & 28,10 & 23,70 \\
\hline
\end{tabular}

\section{Nitrato e Fosfato}

Foi verificada a variação nictemeral para os dois compostos sem apresentar, entretanto, nenhum padrão definido. O nitrato variou de $0,04 \mathrm{a} 0,54 \mu \mathrm{M}$ no verāo, e de 0,03 a $0,30 \mu \mathrm{M}$ no inverno. $O$ fosfato variou de 0,04 a 0,22 $\mu \mathrm{M}$ no inverno, e de $0,05 \mathrm{a} \mathrm{0,19} \mu \mathrm{M}$ no verão (Tabs $5 \mathrm{e} 6$ ).

Tabela 5. Concentração de nitrato $(\mu \mathrm{M})$ da superfície durante as horas de coleta de um dia

\begin{tabular}{llllllllll}
\hline Hora & FEV. & MAR. & ABR. & JUN. & JUL. & AGO. & MAR. & aI. \\
\hline $06: 00$ & 0,05 & 0,54 & 0,31 & 0,03 & 0,26 & 0,17 & 0,18 & 0,02 \\
$09: 00$ & 0,08 & 0,17 & 0,22 & 0,11 & 0,13 & 0,08 & 0,20 & 0,03 \\
$12: 00$ & 0,10 & 0,39 & 0,19 & 0,04 & 0,01 & 0,10 & 0,14 & 0,02 \\
$15: 00$ & 0,04 & 0,49 & 0,19 & 0,15 & 0,24 & 0,17 & 0,09 & 0,04 \\
$18: 00$ & 0,09 & 0,22 & 0,10 & 0,05 & 0,30 & 0,09 & 0,13 & 0,05 \\
$21: 00$ & 0,10 & 0,49 & 0,10 & 0,22 & 0,18 & 0,11 & 0,23 & 0,04 \\
$24: 00$ & 0,07 & 0,49 & 0,20 & 0,15 & 0,14 & 0,07 & 0,19 & 0,05 \\
$03: 00$ & 0,04 & - & 0,19 & 0,13 & 0,10 & 0,08 & 0,21 & 0,08 \\
\hline
\end{tabular}

Marés

A maré média alcança o nível de $1,20 \mathrm{~m}$ e as grandes marés o nível de $2,00 \mathrm{~m}$ (Schaeffer-Novelli, 1976). Os valores registrados para os diferentes níveis de marés, variaram de 0,43 a $1,58 \mathrm{~m}$ no inverno e 0,42 a $1,45 \mathrm{~m}$ no verão. 
Tabela 6. Concentração de fosfato $(\mu \mathrm{M})$ da superfície durante as horas de coleta de um dia

\begin{tabular}{llllllllll}
\hline Hora & FEV. & MAR. & ABR. & JUN. & JUL. & AGo. & MAR. & OUT. \\
\hline $06: 00$ & 0,11 & 0,19 & 0,23 & 0,09 & 0,11 & 0,09 & 0,08 & 0,02 \\
$09: 00$ & 0,10 & 0,10 & 0,07 & 0,07 & 0,17 & 0,04 & 0,24 & 0,01 \\
$12: 00$ & 0,14 & 0,08 & 0,16 & 0,19 & 0,14 & 0,05 & 0,10 & 0,01 \\
$15: 00$ & 0,11 & 0,03 & 0,12 & 0,08 & 0,22 & 0,05 & 0,10 & 0,01 \\
$18: 00$ & 0,08 & 0,08 & 0,07 & 0,04 & 0,17 & 0,06 & 0,09 & 0,00 \\
$21: 00$ & 0,17 & 0,16 & 0,03 & 0,09 & 0,17 & 0,07 & 0,08 & 0,01 \\
$24: 00$ & 0,09 & 0,12 & 0,14 & 0,09 & 0,17 & 0,06 & 0,11 & 0,01 \\
$03: 00$ & 0,05 & - & 0,07 & 0,06 & 0,17 & 0,05 & 0,13 & 0,01 \\
\hline
\end{tabular}

\section{Precipitação Pluviométrica}

Apresenta um regime caracterizado por um ciclo sazonal bem definido, pelo menos durante o intervalo de tempo considerado, com um máximo no verāo e um mínimo durante o inverno (Tab. 7).

Tabela 7. Precipitação pluviométrica total mensal $(\mathrm{mm})$.

\begin{tabular}{lcc}
\hline \multicolumn{1}{c}{ Mês } & Ano & Precipitação (mm) \\
\hline Fevereiro & 1978 & 242,3 \\
Março & 1978 & 113,6 \\
Abril & 1978 & 106,5 \\
Junho & 1978 & 61,3 \\
Jutho & 1978 & 17,8 \\
Agosto & 1978 & 43,6 \\
Março & 1979 & 358,9 \\
Outubro & 1979 & 96,9 \\
\hline
\end{tabular}

\section{Radiaçāo Solar}

Os dados de radiação solar global mostram valores máximos sempre no verão e os mínimos no inverno, ocorrendo em determinados dias uma acentuada assimetria no ciclo diário (Figs 2 e 3 ).

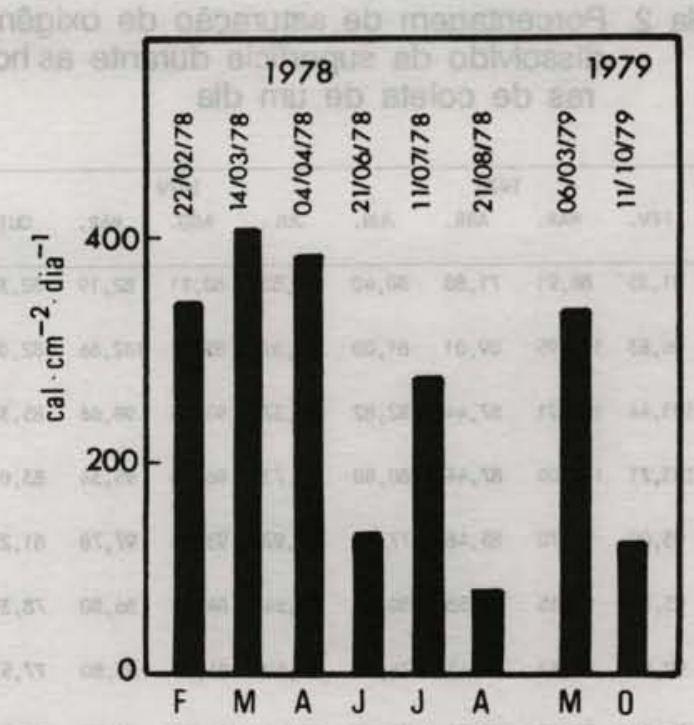

Fig. 2. Radiação solar global ocorrida durante os dias em que foram efetuados os experimentos.

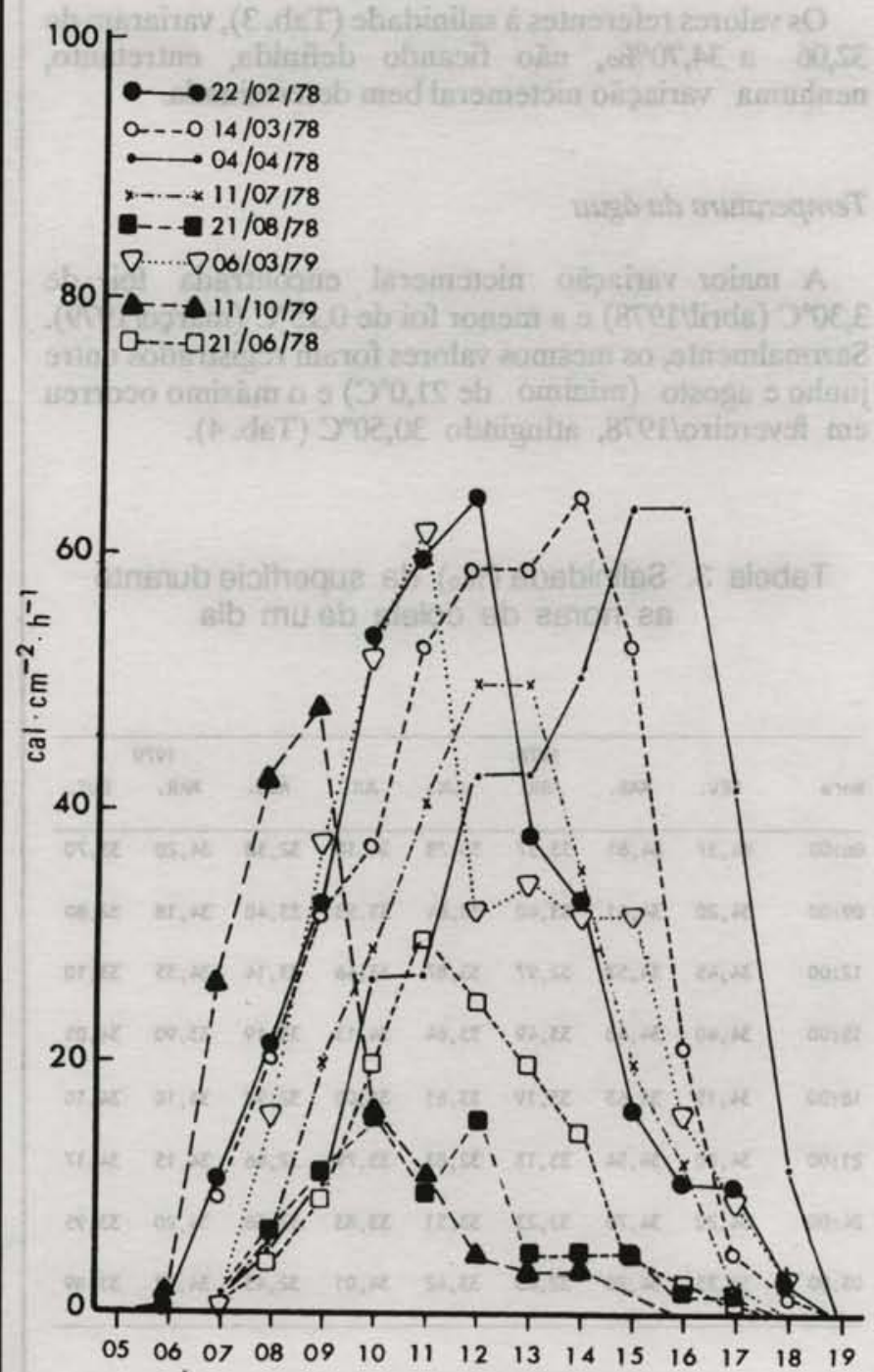

Fig. 3. Curvas diárias da radiação solar global mostrando as diferentes características estacionais. 


\section{Temperatura do $\mathrm{Ar}$}

A amplitude foi de $6,0^{\circ} \mathrm{C}$. A média mensal da temperatura do ar durante os meses em que foram realizados os experimentos se encontra na Tabela 8.

Tabela 8. Média mensal da temperatura do ar $\left({ }^{\circ} \mathrm{C}\right)$ durante os meses em que foram realizados experimentos

\begin{tabular}{l|cc|}
\hline Mês & Ano & Temperatura $\left({ }^{\circ} \mathrm{C}\right)$ \\
\hline Fevereiro & 1978 & 25,82 \\
\hline Março & 1978 & 25,51 \\
\hline Abril & 1978 & 22,80 \\
Junho & 1978 & 19,80 \\
Jutho & 1978 & 21,43 \\
\hline Agosto & 1978 & 20,78 \\
\hline Março & 1979 & 25,93 \\
\hline Outubro & 1979 & 23,94 \\
\hline
\end{tabular}

Parâmetros Biológicos

\section{Produção Primária}

Os resultados determinados para a produção primária nas diferentes épocas do ano, para 12 ou 24 horas (produçāo diurna ou nictemeral), encontram-se nas Figuras 4 a 6 . De uma maneira geral, a variação nictemeral apresentou um padrão relativamente constante para as diferentes épocas do ano (Figs 5-6), ocorrendo muito poucas exceções como em 04/04/78.

A amplitude encontrada foi de 2,71 a 6,85 no verāo; de 3,20 a 7,70 no inverno e de 1,58 a 11,70 nos demais meses estudados (Fig. 5).

As amostras renovadas geralmente mostram valores maiores do que as amostras armazenadas; as diferenças encontradas entre elas variaram de 0,93 até cerca de $50 \%$ (Fig.4).

\section{Clorofila $a$ Total}

A concentração deste pigmento mostrou uma variação muito grande entre as diferentes horas das coletas. Assim, a variação da concentração de clorofila $a$ nas diferentes horas de um mesmo dia foi de 1,48 a $4,80 \mathrm{mg}$ $\mathrm{m}^{-3}$ durante o verão, de1,20 a $2,48 \mathrm{mg} \mathrm{m}^{-3}$ no inverno e de 1,98 a 3,62 $\mathrm{mg} \mathrm{m}^{-3}$ nos demais meses estudados (Fig. 6).

\section{Discussão}

As variaçōes nictemerais relativas à capacidade fotossintética foram bastante pronunciadas, alcançando diferenças na Fmax de 1,58 até 11,70. Ficou demonstrado também que as diferenças quanto aos valores da Fmax, ocorreram independentemente da variação natural da intensidade luminosa, assim como da concentração da clorofila $a$. Segundo alguns autores (Prezelin \& Sweeney, 1978), o conteúdo da clorofila $a$ celular pode mediar parcialmente a fotoadaptação em intensidades abaixo do ponto de compensação e a taxa em que as células alteram o seu conteúdo de clorofila pode determinar, em parte, em quanto tempo o fitoplâncton se adapta às variaçôes dia-a-dia em relação à intensidade luminosa. No nosso caso, entretanto, talvez devido à pequena profundidade $(3,0 \mathrm{a} 4,0 \mathrm{~m})$ e à composiçāo específica do fitoplâncton, não foram verificados claramente estes fatos.

Os resultados obtidos, tanto nos experimentos in situ como nos simulados, foram bastante concordantes, mostrando a ocorrência de um padrão de variação cíclica bem definido. Das oito diferentes épocas em que os experimentos foram realizados, apenas os determinados em março de 1979 e abril de 1978, apresentaram um padrāo de variação diferente dos demais (Figs 4 e 5). Com relação aos experimentos com amostras renovadas e armazenadas, os resultados mostraram geralmente valores maiores para as amostras renovadas, isto é, coletadas a cada três horas (Fig. 4).

Atualmente o modelo comportamental mais aceito para explicar as oscilaçōes das atividades biológicas refere-se à integraçāo do ciclo diurno dos elementos bioquímicos do interior das células e à influência do ambiente mais o efeito da oscilação solar (Parsons et al., 1977). Segundo Prezelin \& Ley (1980), a periodicidade nictemeral da fotossíntese é controlada por um "relógio biológico", isto é, é endogenamente controlada, enquanto que a magnitude e talvez a sincronizaçāo das taxas fotossintéticas nictemerais sejam reguladas pelas variáveis ambientais. Variáveis estas que exerceram seus efeitos em determinados instantes de tempo e tiveram uma determinada duraçāo. Assim, é lógico supor que toda e qualquer alteraçāo ambiental, além de uma dimensão espacial, tem uma dimensão temporal, a qual também deve ter tido influências nos processos de adaptação e evolução dos seres vivos (Paludetti, 1988).

Com relação aos nutrientes, têm sido considerados como o principal fator limitante da produçāo primária, principalmente os compostos do nitrogênio e do fósforo (Thomas, 1967, etc.). A variação do nitrato e do fosfato durante o período nictemeral, foi evidente (Tabs 4 e 5 ) mas não obedeceu a nenhum padrão de variaçāo determinado nas diferentes épocas do ano. Os nutrientes considerados, apesar de fundamentais para o processo fotossintético, não mostraram uma correlação muito grande com a produção primária. Assim, parece que as variaçōes nictemerais nas concentraçōes de nutrientes, como nitrato e fosfato verificadas neste trabalho não foram de amplitude suficiente para justificar de per si as causas fundamentais das variaçōes nictemerais da fotossíntese. 


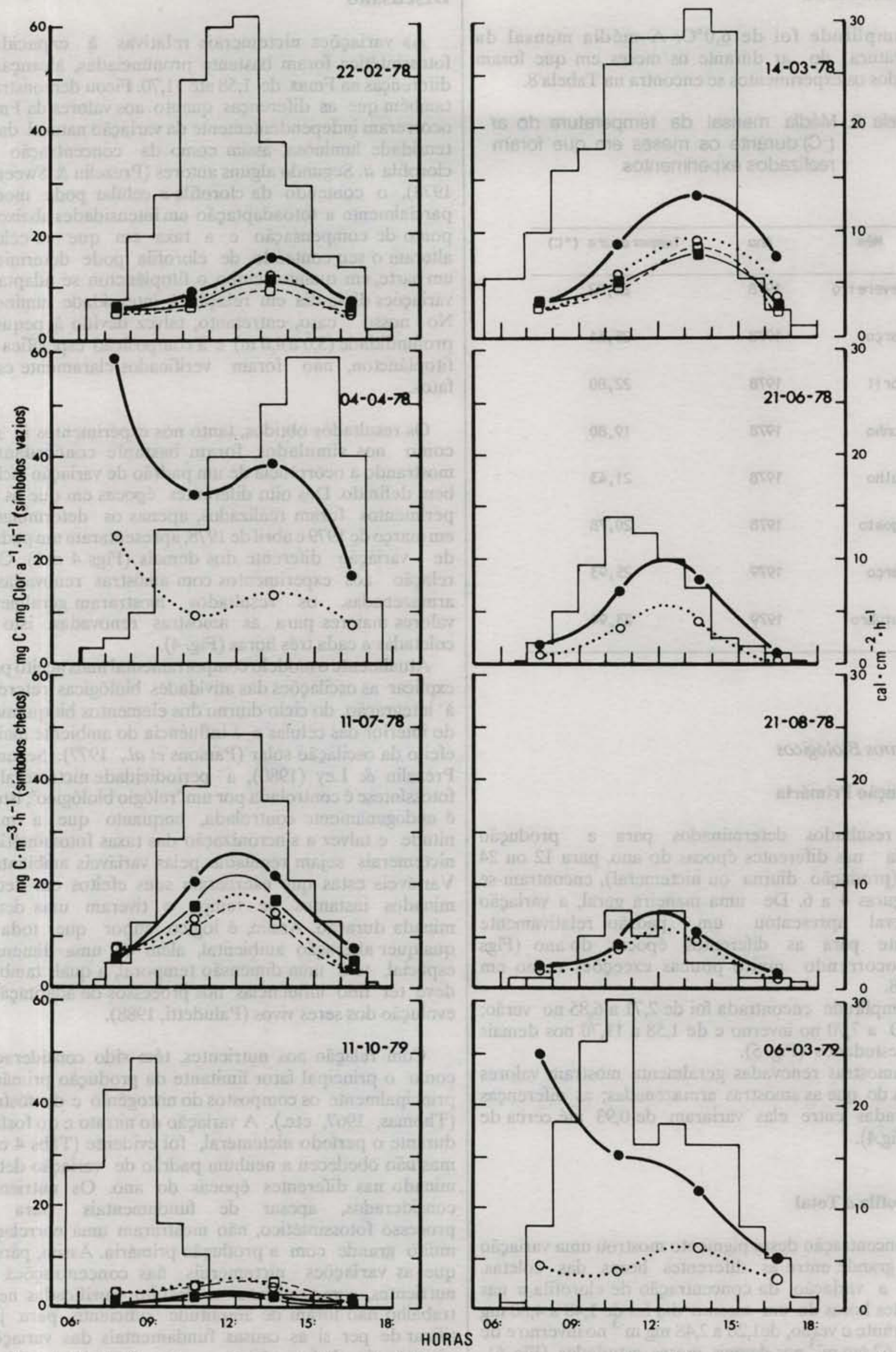

Fig. 4. Variação diurna da produção primária em amostras renovadas (o) e armazenadas (a). 


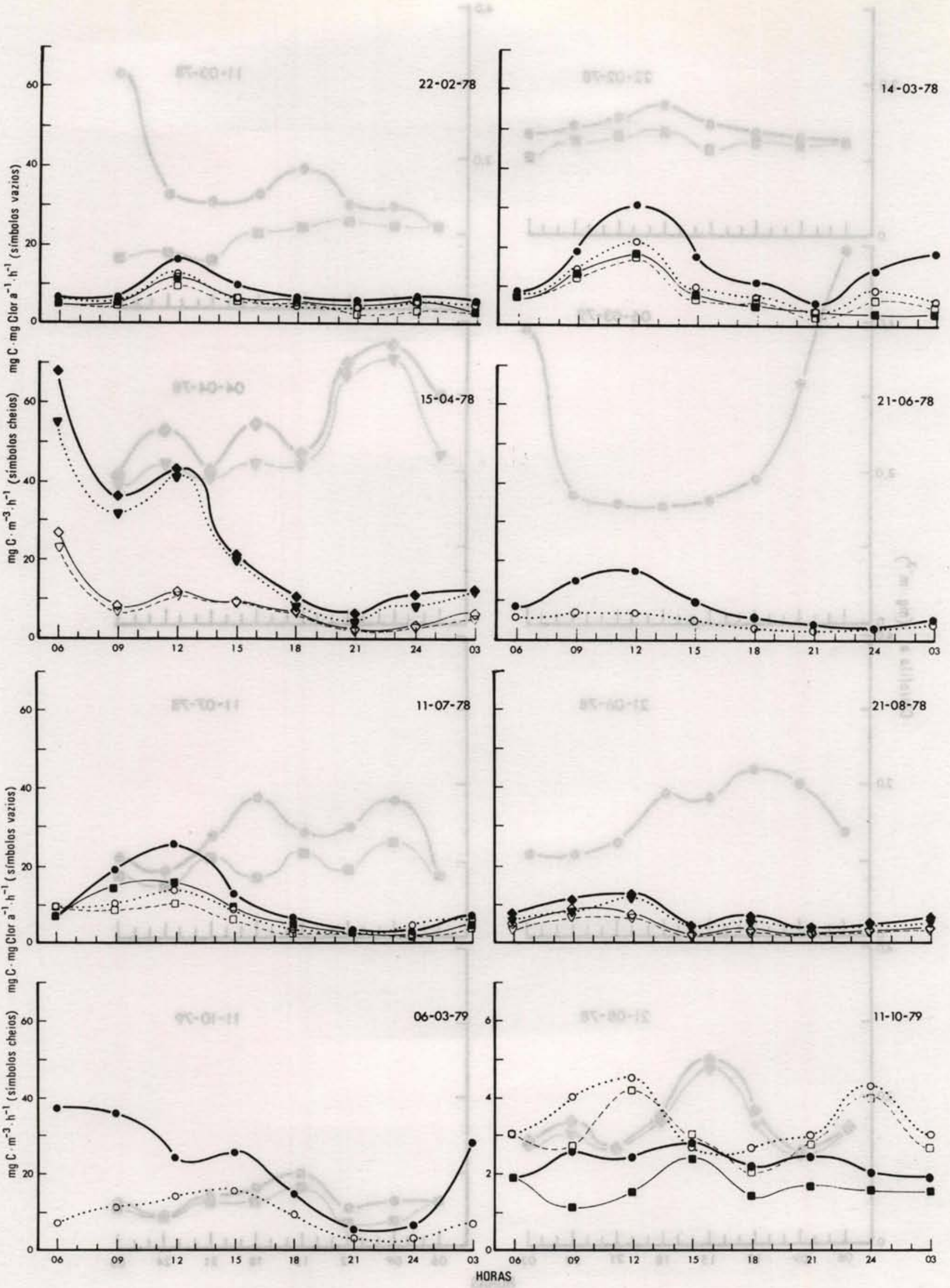

Fig. 5. Variação nictemeral da produção primária em amostras renovadas $(0)$ e armazenadas (a) e amostras do fitoplâncton total $(\diamond)$ e do nanofitoplâncton $(\nabla)$ em condições simuladas. 


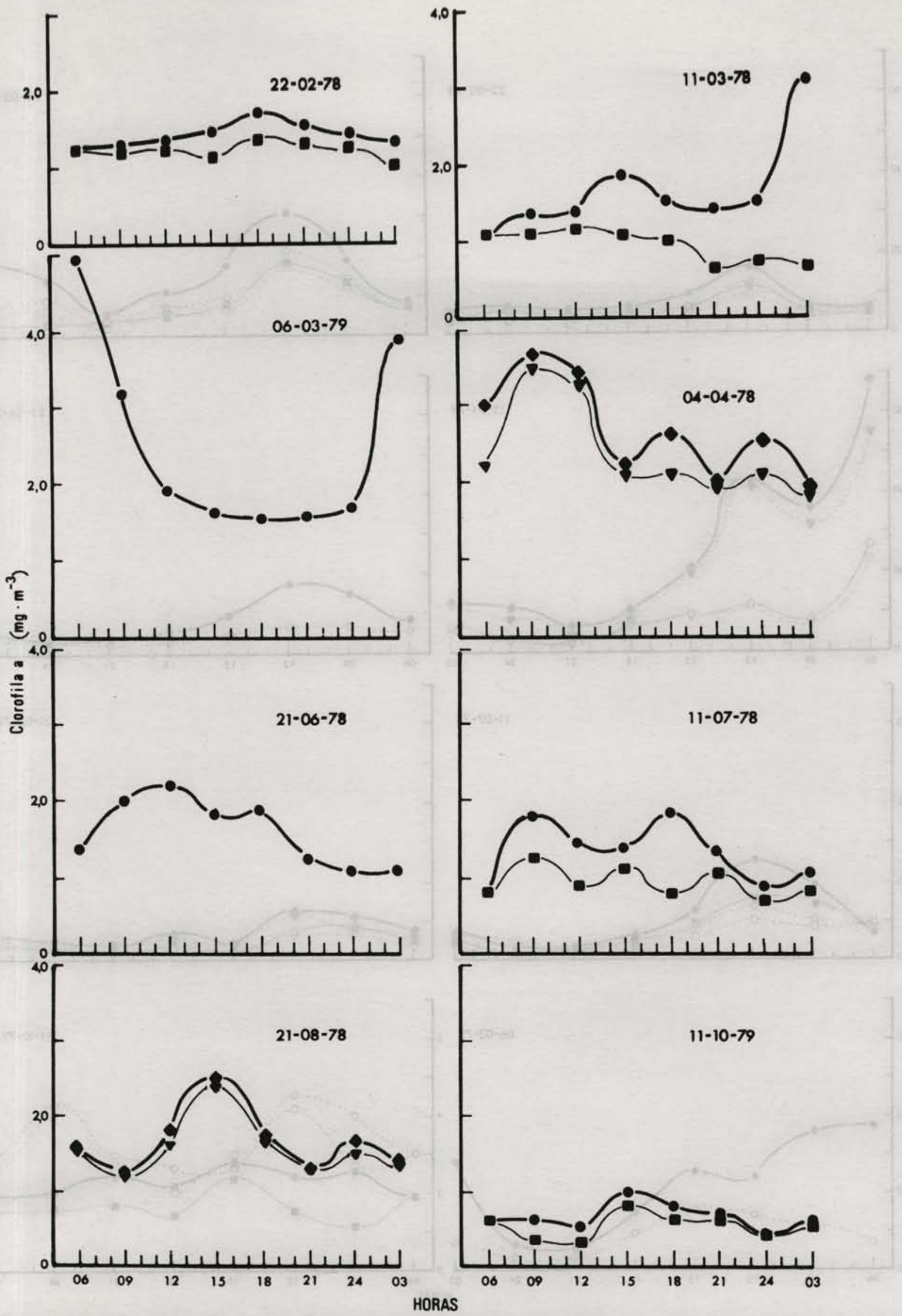

Fig. 6. Variação nictemeral da concentração de clorofila $a$ em amostras renovadas (o) e armazenadas (a) e amostras do fitoplâncton total $(\diamond)$ e do nanofitoplâncton $(\nabla)$. 
Quanto à radiaçāo solar, mostrou ser um dos fatores abióticos que maior influência apresentou sobre o valor da Fmax, devido à característica assimétrica da curva diária e da radiação global durante as diferentes épocas do ano (Fig. 3), além do efeito da nebulosidade parcial da atmosfera, principalmente durante certos períodos do dia. Indiretamente, segundo parece, a radiação solar também influiu, neste caso sobre a própria temperatura da água, o que poderia ter afetado principalmente o processo respiratório.

Pelos dados obtidos, verifica-se que a radiação solar causou um ligeiro aquecimento durante o período diurno $(12: 00 \mathrm{~h})$. A diferença encontrada entre o valor máximo e o mínimo foi da ordem de $6,0^{\circ} \mathrm{C}$ (Tab. 3). Quanto à amplitude de variação da temperatura da água não foi muito elevada $\left(0,15\right.$ a $\left.3,30^{\circ} \mathrm{C}\right)$, porém é provável que a mesma tenha influência direta sobre determinadas espécies mais sensíveis, como por exemplo sobre Phaeodactylum tricornutum Bohlin (Vieira, 1975), além de produzir um possível controle sobre o aumento ou decréscimo da clorofila $a$ celular; assim, em temperaturas mais elevadas (no verảo), o conteúdo da clorofila $a$ variou de 1,20 a $2,48 \mathrm{mg} \mathrm{m}^{-3}$. Estando o ponto de coleta situado a uma profundidade de apenas $4,0 \mathrm{~m}$, é improvável que ocorra uma estratificação térmica como a verificada a partir de 15,0 m (Teixeira, 1973; 1979), assim, as variaçōes da clorofila $a$ celular, provavelmente nāo estejam apenas ligadas à otimização da utilização da energia solar disponível nos diferentes dias.

Além da influência dos fatores exógenos (radiação solar, temperatura, nutrientes, etc.), os resultados obtidos indicam claramente que também ocorreu a influência dos fatores endógenos sobre a variação nictemeral, bastando verificar as curvas obtidas em condiçōes simuladas de temperatura e energia luminosa constantes (Fig. 5), que apresentam padrōes muito similares quanto às variaçōes diurnas em relação às populações incubadas in situ, quando ocorreram grandes variaçōes dos parâmetros ambientais, particularmente quanto à radiação solar.

\section{Referências bibliográficas}

ASCHOFF, J. 1981. Handbook of behavioral neurobiology. Biological rhythms. New York, Plenum Press. v.4.

BRAY, G. A. 1960. A simple liquid scintillator for counting aqueous solutions in liquid scintillation. Anal. Biochem.,1:279-289.

DOTY, M. S. \& OGURI, M. 1957. Evidence for a photosynthetic daily periodicity. Limnol. Oceanogr., 2:37-40.

GARGAS, E.; HARE, I.; MARTENS, P. \& EDLER, L. 1979. Diel changes in phytoplankton photosynthetic efficiency in brackish waters. Mar. Biol., 52:113-122.
HARDING Jr; L. W.; PREZELIN, B. B.; SWEENEY, B.M. \& COX, J.I. 1982. Diel oscillations of the photosynthesis-irradiance (P-I) relationship in natural assemblages of phytoplankton. Mar. Biol., 67:167-178.

HASTINGS, J. W.; ASTRACHAN, L. \& SWEENEY, B. M. 1961. A persistent daily rhythm in photosynthesis. J. Gen. Physiol., 45:69-76.

MULLIN, J. B. \& RILEY, J. P. 1955. The spectrophotometric determination of nitrate in natural waters, with particular reference to sea water. Anal. Chim. Acta., 12:464-481.

PALUDETTI, L. A. 1988. Conceitos fundamentais. In: Cipolla-Neto, J.; Marques, N. \& Menna-Barreto, L. S., eds Introdução ao estudo da cronobiologia. São Paulo, Icone Editora. p. 25-34.

PARSONS, T.R.; TAKAHASHI, M. \& HARGRAVE, B. 1977. Biological oceanography processes. Oxford, Pergamon Press. 332 p.

PREZELIN, B.B. \& SWEENEY, B.M. 1978. Photoadaptation of photosynthesis on Gonyaulax polyedra. Mar. Biol., 48:27-35.

\& LEY, A. C. 1980. Photosynthesis and chlorophyll $a$ fluorescence rhythms of marine phytoplankton. Mar. Biol., 55:295-307.

SCHAEFFER-NOVELLI, Y. 1976. Alguns aspectos ecológicos e análise da população de Anomalacardia brasiliana (Gmelin, 1791) Molusca Bivalvia, na praia do Saco da Ribeira, Ubatuba, Estado de São Paulo. Tese de doutorado. Universidade de São Paulo, Instituto de Biociências. 119 p.

STRICKLAND, J. D. H. \& PARSONS, T. R. 1968. A practical handbook of sea water analysis. Bull. Fish. Res. Bd Can., (167):1-310.

TEIXEIRA, C. 1973. Preliminary studies of primary production in the Ubatuba region (Lat. $23^{\circ} 30^{\prime} \mathrm{S}$ Long. $\left.45^{\circ} 06^{\prime} \mathrm{W}\right)$, Brazil. Bolm Inst. oceanogr., S Paulo., 22:49-58.

1979. Produção primária e algumas consideraçōes ecológicas da regiāo de Ubatuba (Lat. 233' ' - Long. $45^{\circ} 06^{\prime} \mathrm{W}$ ), Brasil. Bolm Inst. oceanogr., S Paulo., 28(2):23-28.

1980. Estudo quantitativo da produção primária, clorofila $a$ e parâmetros abióticos em relação à variação temporal (Lat. $23^{\circ} 30^{\prime} \mathrm{S}$ - Long. $45^{\circ} 06^{\prime} \mathrm{W}$ ). Tese de livre-docência. Universidade de São Paulo, Instituto Oceanográfico. 243 p.

1982. A influência da variaçāo nictemeral e sazonal sobre as curvas de luz-fotossíntese. Bolm Inst. oceanogr., S Paulo, 31(1):55-67. 
THOMAS, W. H. 1967. The nitrogen nutrition of phytoplankton in the northeastern tropical Pacific Ocean. In: PROCEEDINGS OF THE INTERNATIONAL CONFERENCE ON TROPICAL OCEANOGRAPHY, Miami Beach, 1965. Miami, University of Miami. p. 280-289. (Studies in Tropical Oceanography, $\mathrm{n}^{2} 5$ ).
VIEIRA, A. H. A. 1975. Estudos experimentais em fitoplâncton marinho. Culturas e aspectos ecofisiológicos. Dissertação de mestrado, Universidade de São Paulo, Instituto Oceanográfico. 115 p.

(Recebido em 10-10-89; aceito em 0404-91) 